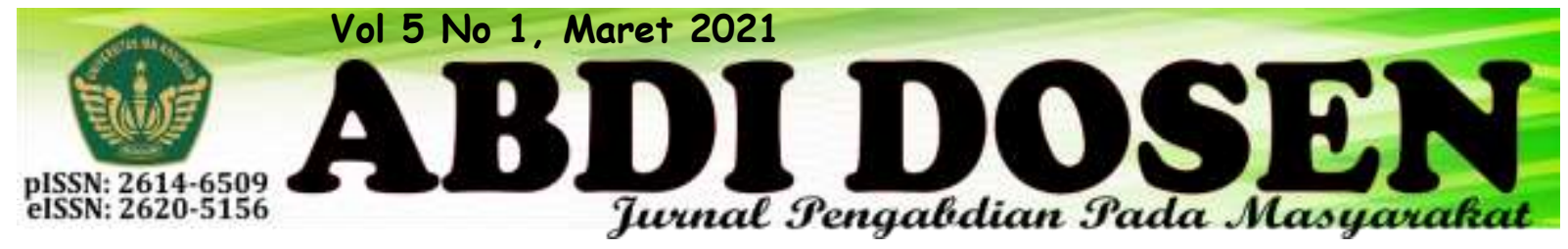

\title{
EDUKASI GIZI, PEMBERIAN TABLET TAMBAH DARAH (TTD) DAN PEMBERIAN MAKANAN TAMBAHAN PADA IBU HAMIL DI ERA PANDEMI COVID-19 DI WILAYAH KERJA PUSKESMAS 23 ILIR PALEMBANG
}

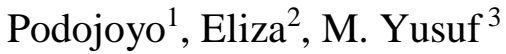 \\ podojoyo@poltekkespalembang.ac.id ${ }^{1}$ \\ eliza_limar@yahoo.co.id ${ }^{2}$ \\ myusuf@poltekkespalembang.ac.id ${ }^{3}$ \\ Prodi D-III Gizi Politeknik Kesehatan Kementerian Kesehatan Palembang 1,2,3
}

\begin{abstract}
ABSTRAK
Masa kehamilan merupakan masa pertumbuhan dan perkembangan janin menuju masa kelahiran sehingga gangguan gizi yang terjadi pada masa kehamilan akan berdampak besar bagi kesehatan ibu maupun janin. Salah satu masalah gizi yang banyak terjadi pada ibu hamil adalah anemia yang merupakan masalah gizi mikro terbesar dan tersulit diatasi di seluruh dunia. Pengentasan masalah pada ibu hamil anemia adalah dengan memberikan edukasi gizi tentang gizi yang baik untuk ibu hhamil, pemberian Tablet Tambah Darah (TTD) dan pemberian makanan tambahan pada ibu hamil. Edukasi gizi terbukti efektif meningkatkan pengetahuan ibu hamil dan kader. Kegiatan pengabdian kepada masyarakat ini bertujuan untuk meningkatkan pengetahuan dan keterampilan ibu hamil dan kader dalam pencegahan dan penanganan anemia pada ibu hamil di era pandemi Covid 19. Metode yang digunakan adalah penyuluhan gizi tentang makanan bergizi untuk ibu hamil dan pemberian Tablet Tambah Darah. Pre dan Post test sebelum dan setelah diberikan edukasi gizi. Hasil kegiatan berdampak positif bagi peserta dimana sebagian besar ibu hamil dan kader mengalami peningkatan pengetahuan yang signifikan setelah diberikan penyuluhan.
\end{abstract}

\section{Kata Kunci: Anemia, Edukasi Gizi, Ibu Hamil, Kader}

\section{ABSTRACT}

The period of pregnancy was a period of growth and development of the fetus towards the time of birth so that nutritional disorders that occur during pregnancy will have a major impact on the heath of both the mother and the fetus. One of the nutritional problems that often occur in pregnant women was anemia which was the biggest and most difficult micronutrient problem to overcome in the word. Alleviating problems in anemia pregnant women was by providing nutrition education about nutrition pregnant women, giving Tablet Tambah Darah (TTD) dan giving additional food to pregnant women. Nutrition education was proven to be effevtive in increasing the knowledge of pregnant women and kader. This community service activity aims to increase the knowledge and skills of pregnant women and kader in the prevention and management of anema in pregnant women in the Covid 19 pandemic era. The methods used were nutritional education about nutritious food for pregnancy and provision of TTD dan PMT. Pre and post test before and after nutrition education. The result of the activity had a positive 
impact on the participants where most of the pregnant women and kader experienced a significant increase in knowledge after being given counseling.

\section{Keywords: Anemia, nutrition education, pregnant women, kader.}

\section{PENDAHULUAN}

Anemia gizi besi pada ibu hamil merupakan suatu keadaan dimana secara physiologi mengalami kekurangan zat besi yang ditandai dengan rendahnya kadar hemoglobin di bawah normal yaitu < 11g/l. Anemia gizi besi menjadi masalah gizi kesehatan masyarakat yang berat apabila prevalensinya $>40 \%$ terjadi di suatu wilayah (WHO, 2001).

Badan Kesehatan Dunia melaporkan bahwa pada tahun 2005 terdapat $52 \%$ ibu hamil mengalami anemia di negara berkembang (WHO 2005). Di Indonesia prevalensi anemia pada ibu hamil juga masih tinggi yaitu $37,1 \%$ atau satu diantara tiga ibu hamil di Indonesia menderita anemia (Balitbangkes, 2013).

Faktor penyebab anemia gizi besi pada ibu hamil adalah faktor genetik seperti penyakit kelainan darah yang dibawa sejak lahir, kurangnya konsumsi zat besi, asam folat, vitamin B12 dari makanan, meningkatnya kebutuhan karena kehamilan dan adanya zat penghambat penyerapan. Selain itu juga diakibatkan kurang energi kronis (KEK), umur kehamilan, kepatuhan mengkonsumsi tablet tambah darah, penyakit infeksi dan status sosial ekonomi (Aditianti, dkk 2015).

\section{METODE PELAKSANAAN}

Kegiatan pengabdian r pada
masyarakat ini dilaksanakan dengan
memberikan edukasi gizi dengan metode
penyuluhan, pemberian Tablet Tambah
Darah dan pemberian makanan tambahan
untuk ibu hamil melalui beberapa tahapan

Menurut Riset Kesehatan Dasar (Riskesdas) tahun 2018 terdapat 48,9\% ibu hamil mengalami anemia walaupun sebagian besar sudah mendapat tablet tambah darah (TTD) sebanyak 73,2 \%. Program pemerintah berupa intervensi pemberian maknanan tambahan (PMT) pada ibu hamil masih rendah yaitu sebesar $25,2 \%$ selebihnya $74,8 \%$ tidak mendapat PMT. Data dari Dinas Kesehatan Kota Palembang tahun 2018 jumlah kasus anemia pada ibu hamil sebanyak 200 terdapat di wilayah kerja Puskesmas Bukit Kecil (Puskesmas Merdeka dan Puskesmas 23 Ilir Palembang), sebanyak 195 di wilayah kerja Puskesmas Kertapati dan sebanyak 172 di wilayah kerja Puskesmas Seberang Ulu I (Dinas Kesehatan Kota Palembang, 2018).

Berdasarkan uraian diatas dapat diketahui bahwa prevalensi ibu hamil yang mengalami anemia masih tinggi. Salah satu upaya untuk membantu mengatasi masalah anemia pada ibu hamil adalah penyuluhan kepada ibu hamil tentang gizi untuk ibu hamil dan pemberikan Tablet Tambah Darah (TTD), serta memberikan pelatihan kepada para kader agar dapat memantau ibu hamil patuh dalam mengonsumsi TTD.

mulai dari persiapan, pelaksanaan sampai evaluasi kegiatan, antara lain sebagai berikut:

1. Tahap Persiapan :

Mencari lokasi puskesmas yang memenuhi kriteria sebagai 
mitra yaitu angka kasus anemia dipuskesmas tersebut tinggi. Mengurus administrasi perizinan di lokasi puskesmas yang memenuhi kriteria. yaitu di Puskesmas 23 Ilir Palembang. Mempersiapkan tempat dan sarana pelaksanaan pendidikan kesehatan, misalnya tempat akan dilakukan penyuluhan, sarana belajar menggunakan kursi, infokus, leaflet, buku Tambet Tambah Darah, makanan tambahan untuk ibu hamil, hand sanitisier dan masker medis. Mempersiapkan materi, alat bantu penyuluhan dan jadwal pelaksanaan serta mempelajari materi yang akan disampaikan. Persiapan peserta dengan mengundang ibu hamil dan para kader untuk mengikuti penyuluhan gizi untuk ibu hamil dan anemia. Membuat rencana pelaksanaan kegiatan dengan pihak Puskesmas 23 Ilir Palembang.

2. Tahap Pelaksanaan:

Pelaksanaan kegiatan pengabdian kepada masyarakat dilakukan pada tanggal 14 November 2020. Acara dimulai dengan pembukaan kegiatan pengabmas yang dipandu oleh mahasiswa Prodi D-III Gizi. Kemudian kata sambutan dari Dosen Prodi D-III Gizi dan dari Pihak Puskesmas 23 Ilir. Lalu pengambilan darah untuk mengetahui kadar zat besi pada ibu hamil yang dilakukan oleh petugas kesehatan dari pihak Puskesmas 23 Ilir Palembang. Sebelum diberikan penyuluhan gizi, dilakukan pengisian kuesioner pre test oleh ibu hamil dan kader. Kuesioner yang diberikan berisi 20 soal pilihan ganda tentang gizi dan anemia pada ibu hamil. Setelah pengisian kuesioner, diberikan edukasi gizi melalui penyuluhan tentang makanan bergizi untuk ibu hamil, pencegahan dan penanganan anemia pada ibu hamil yang dilakukan oleh tim dosen dari Prodi D-III Gizi Poltekkes Kemenkes Palembang. Para peserta antusias dalam mengikuti kegiatan penyuluhan ini. Hal ini terlihat dengan banyaknya pertanyaan yang diajukan oleh ibu hamil dan kader. Setelah diberikan penyuluhan, acara selanjutnya adalah pemberian Tablet Tambah Darah untuk Ibu Hamil serta Pemberian Makanan Tambahan untuk ibu hamil berupa susu untuk ibu hamil.

3. Tahap Evaluasi

Pada tahap ini dilakukan kesepakatan agar ibu hamil mengkonsumsi makanan yang bergizi, mengkonsumsi Tablet Tambah Darah serta mengkonsumsi makanan tambahan berupa susu. Dilakukan juga kesepakatan dengan kader agar melakukan pendampingan kepada ibu hamil dalam mengkonsumsi TTD, konsumsi PMT ibu hamil serta menyampaikan juga kepada ibu hamil yang lain yang tidak hadir pada waktu penyuluhan tentang makanan yang bergizi untuk ibu hamil. Evaluasi dalam bentuk post tes berupa kuesioner untuk menilai apakah kegiatan ini memiliki manfaat terhadap 
peningkatan pemahaman, perubahan perilaku dan sikap ibu hamil dan kader yang ada di wilayah kerja Puskesmas 23 Ilir Palembang. Hasil evaluasi dilaporkan kepada Direktur Poltekkes Kemenkes Palembang dan pihak-pihak yang berkepentingan pada akhir pelaksanaan kegiatan pengabdian

\section{HASIL dan PEMBAHASAN}

Kegiatan pengebdian kepada masyarakat ini telah dilaksanakan selama 1 hari pada bulan November 2020. Kegiatan tersebut melibatkan 22 orang ibu hamil dan 16 orang kader di wilayah kerja Puskesmas 23 Ilir Palembang.

\section{Hasil pemeriksaan kadar hemoglobin ibu hamil}

Berdasarkan pemeriksaan darah, ratarata kadar hemoglobin pada ibu hamil adalah 10,5 g/dl, kadar hemoglobin terendah adalah $8,0 \mathrm{~g} / \mathrm{dl}$. Hal ini terlihat bahwa kadar hemoglobin ibu hamil di wilayah kerja Puskesmas 23 Ilir Palembang masih banyak yang rendah atau mengalami anemia. Selama kehamilan, kebutuhan zat besi meningkat sebanyak $30 \%$ kepada masyarakat. Evaluasi kegiatan program disampaikan untuk memberikan gambaran hasil pelaksanaan kegiatan pengabdian kepada masyarakat dan juga untuk mendapatkan masukan dari berbagai pihak tentang pelaksanaan kegiatan dan perbaikan kegiatan pada masa mendatang.

dibandingkan tidak hamil. Oleh karena itu ibu hamil harus mendapatkan tambahan zat besi berupa suplementasi zat besi (MoenchPfanner et al, 2005). Rekomendasi konsumsi suplemen zat besi di Indonesia adalah $60 \mathrm{mg}$ besi elemental dan 0,25 mg asam folat per hari atau 1 tablet perhari yang dikonsumsi paling sedikit 90 tablet selama kehamilan (MCAI, 2015).

Status kekurangan energi kronis (KEK) pada ibu hamil dapat berdampak pada kejadian anemia pada ibu hamil juga pada kejadian BBLR dan stunting (Dekker et al. 2010). Untuk itu selain pemberian Tablet tambah darah juga perlu dilberikan makanan tambahan untuk ibu hamil.

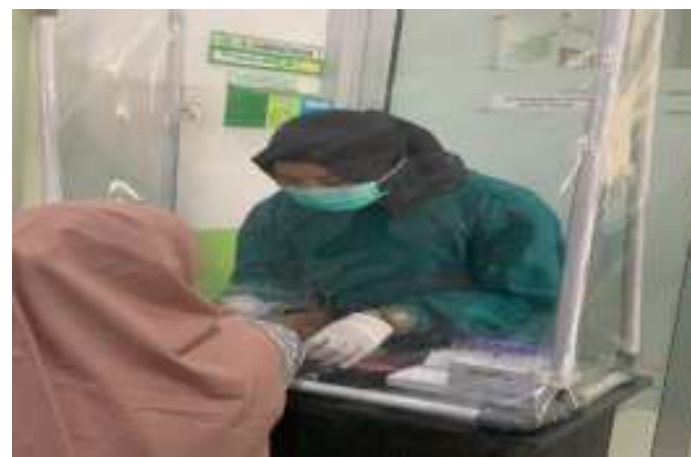

Gambar 1. Pengambilan darah untuk pemeriksaan $\mathrm{Hb}$

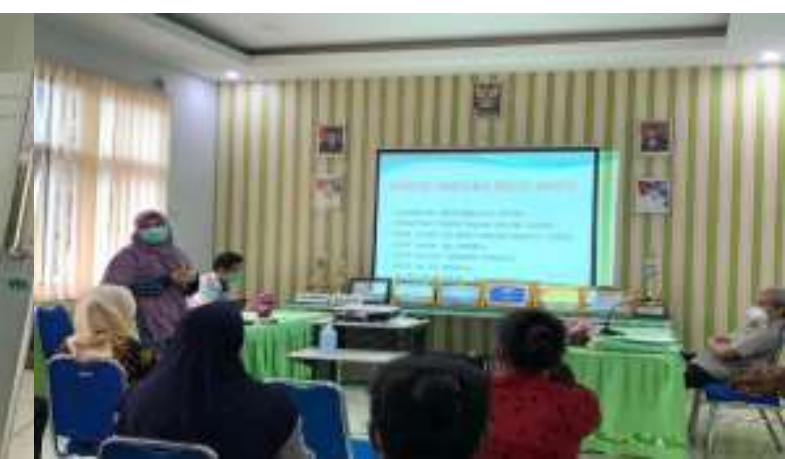

Gambar 2. Penyuluhan Gizi dan anemia untuk Ibu hamil dan kader 


\section{Hasil pre test dan post test ibu hamil}

Hasil pre test dan post test pengetahuan ibu hamil dapat dilihat pada tabel 1.

Tabel 1. Hasil Pengetahuan Pre Test dan Post Test Ibu Hamil di Wilayah Kerja Puskesmas 23 Ilir Palembang

\begin{tabular}{lcccc}
\hline \multirow{2}{*}{$\begin{array}{c}\text { Pengetahuan Ibu } \\
\text { Hamil }\end{array}$} & \multicolumn{2}{c}{ Pre Test } & \multicolumn{2}{c}{ Post Test } \\
\cline { 2 - 5 } & $\mathrm{n}$ & $\%$ & $\mathrm{n}$ & $\%$ \\
\hline Baik & 5 & 22,7 & 10 & 45,5 \\
\hline Cukup & 12 & 54,6 & 11 & 50,0 \\
\hline Kurang & 5 & 22,7 & 1 & 4,5 \\
\hline \multicolumn{1}{c}{ TOTAL } & 22 & 100 & 22 & 100 \\
\hline
\end{tabular}

Pengetahuan ibu hamil dibagi menjadi 3 kategori. Pengetahuan ibu hamil dikatakan baik bila skor nilainya lebih dari $\geq 76$, dikatakan cukup bila skor nilainya antara 56-75 dan dikatakan kurang bila skor nilainya $<56$.

Berdasarkan Tabel 1 dapat dilihat bahwa terjadi peningkatan pengetahuan ibu hamil dengan kategori baik dari $5(22,7 \%)$ sebelum diberi penyuluhan meningkat menjadi $10 \quad(45,5 \%)$ setelah diberi penyuluhan. Pengetahuan ibu dengan dengan kategori cukup sebelum diberi penyuluhan sebesar $12(54,6 \%)$ menurun menjadi 11 (50,0\%). Pengetahuan ibu hamil dengan kategori kurang sebelum diberi penyuluhan sebesar $5(22,7 \%)$ menurun menjadi $1(4,5 \%)$.

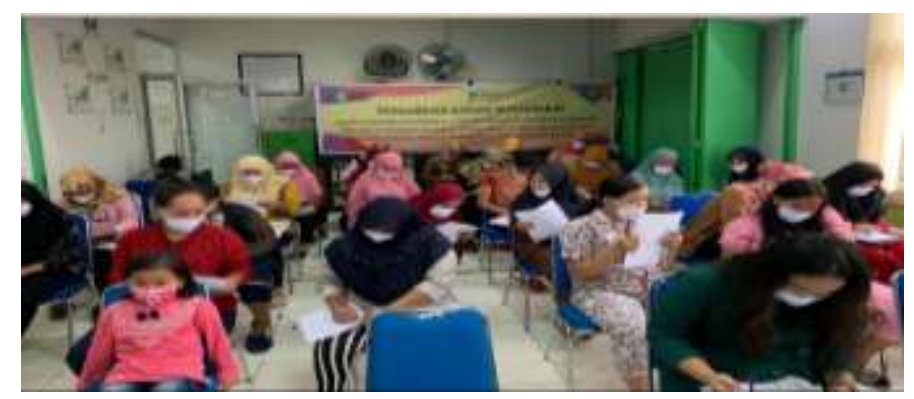

Gambar 3. Pengisian kuesioner pre dan post test

\section{Hasil pre test dan post test kader}

Hasil pre test dan post test kader dapat dilihat pada tabel 2.

Tabel 2. Pengetahuan Pre Test dan Post Test Kader di Wilayah Kerja Puskesmas 23 Ilir Palembang

\begin{tabular}{lcccc}
\hline \multirow{2}{*}{ Pengetahuan Kader } & \multicolumn{2}{c}{ Pre Test } & \multicolumn{2}{c}{ Post Test } \\
\cline { 2 - 5 } & $\mathrm{n}$ & $\%$ & $\mathrm{n}$ & $\%$ \\
\hline Baik & 6 & 37,5 & 10 & 62,5 \\
\hline Cukup & 8 & 50,0 & 6 & 37,5 \\
\hline Kurang & 2 & 12,5 & 0 & 0,0 \\
\hline \multicolumn{1}{c}{ TOTAL } & 16 & 100 & 16 & 100 \\
\hline
\end{tabular}

Pengetahuan kader juga dibagi menjadi 3 kategori. Pengetahuan kader dikatakan baik bila skor nilainya lebih dari $\geq 76$, dikatakan cukup bila skor nilainya 
antara 56-75 dan dikatakan kurang bila skor nilainya $<56$.

Berdasarkan Tabel 2 dapat dilihat bahwa terjadi peningkatan pengetahuan kader dengan kategori baik dari 6 (37,5\%) sebelum diberi penyuluhan meningkat menjadi $10 \quad(62,5 \%)$ setelah diberi penyuluhan. Pengetahuan ibu dengan dengan kategori cukup sebelum diberi penyuluhan sebesar $8(50,0 \%)$ menurun menjadi $6(37,5 \%)$. Pengetahuan ibu hamil dengan kategori kurang sebelum diberi penyuluhan sebesar $2(12,5 \%)$ menurun menjadi $0(0,0 \%)$.

Walaupun terjadi peningkatan pengetahuan dan pemahaman ibu hamil dan kader tidak terlalu besar, tetapi dengan dibekali booklet materi dan leaflet, ibu hamil dan kader dapat memahami kembali materi yang telah dipaparkan secara

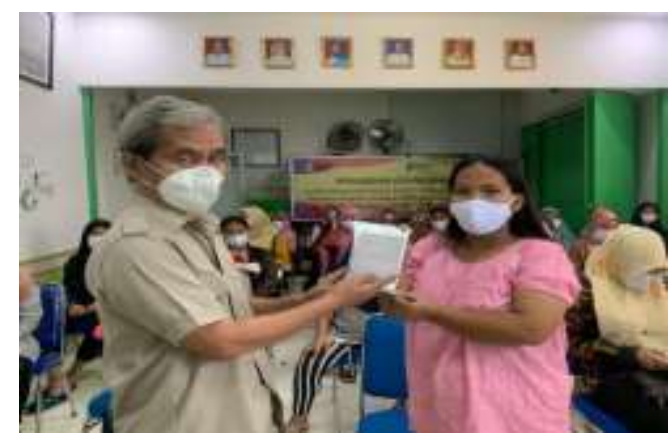

mandiri di rumah. Pemilihan media booklet sebagai media pendukung dalam pemaparan mengacu pada efektivitas media booklet untuk meningkatkan pengetahuan dalam penyuluhan (Puspitaningsum et al, 2017; Zulaekah, 2012). Faktor lain yang mempengaruhi pemahaman pada ibu hamil dan kader adalah media yang digunakan pada saat pemaparan materi. Sebetulnya tidak hanya media power point dan booklet yang digunakan dalam melakukan penyuluhan akan tetapi akan lebih maksimal bila ditambahkan media audiovisual berupa video di dalam prose pemaparan materi (Atmadja et al, 2020).

Kegiatan pengabdian pada masyarakat ditutup dengan kegiatan pemberian Tablet Tambah Darah (TTD) dan Pemberian Makanan Tambahan (PMT) berupa susu untuk ibu hamil.

Gambar 3. Pemberian Makanan Tambahan (PMT) dan Tablet Tambah Darah (TTD) untuk Ibu Hamil

\section{KESIMPULAN}

Kegiatan pengabdian kepada masyarakat yang dilaksanakan pada ibu hamil dan kader di wilayah kerja Puskesmas 23 Ilir Palembang berjalan dengan lancar dengan mengikuti protokol kesehatan. Hasil dari kegiatan telah memberikan dampak positif bagi ibu hamil dan kader dimana sebagian besar ibu hamil dan kader

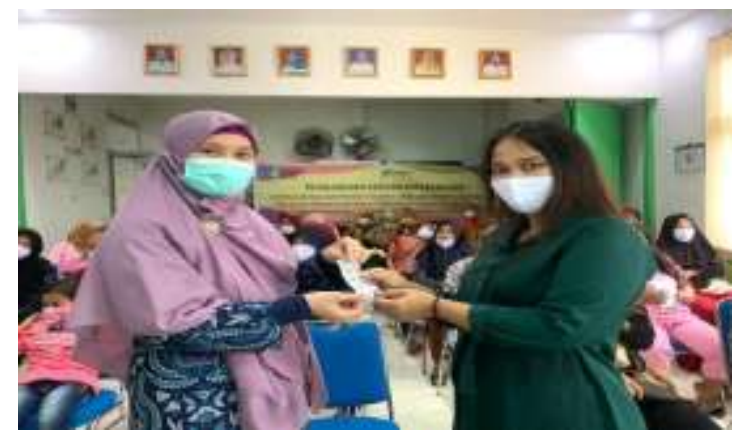

mengalami peningkatan pengetahuan yang signifikan setelah mengikuti penyuluhan gizi sebagai upaya pencegahan dan anemia pada ibu hamil. Agar pengetahuan dan keterampilan ibu hamil dan kader dalam mencegah dan mengatasi anemia, maka perlu dilaksanakan penyuluhan secara terjadwal dan rutin. 


\section{DAFTAR PUSTAKA}

Aditianti, Permanasri Y, Julianti ED. 2015. Pendampingan Minum Tablet Tambah Darah (TTD) Dapat Meningkatkan Kepatuhan Konsumsi TTD Pada Ibu Hamil Anemia. Penelitian Gizi dan Makanan. Vol 38 No. http://ejournal.litbang.kemkes.go.id/i ndex.php/pgm/article/view/4424/0.

Atmadja TFA, Sulistyaningsih D, Mahmudah IR, 2020. Edukasi Gizi Seimbang Sebagai Perisai Penularan Covid-19 Pada Kader Posyandu Bina Sejahtera dan Posyandu Tulip. Abdi Dosen Jurnal Pengabdian Pada Masyarakat. Vol. 4 no. 4: 397-404

Badan. Penelitian dan Pengembangan Kesehatan Kementerian Kesehatan RI. 2013. Riset Kesehatan Dasar 2013. Jakarta: Kemenkes RI. . 2018. Riset Kesehatan Dasar 2013. Jakarta: Kemenkes RI.

Dekker LH, Mora-Plazas M, Marin C, Baylin A, Villamo E. 2010. Stunting associated with poor socioe conomic and maternal nutrition status and respiratory morbidity in Colombian school childeran. Food Nutr Bull 31(2): 242-50 